\title{
The CS-US interval (ISI) function in rabbit nictitating membrane response conditioning with very long intertrial intervals
}

\author{
CHARLES F. LEVINTHAL, ROSS H. TARTELL, CARRIE M. MARGOLIN, \\ and HOWARD FISHMAN \\ Hofstra University, Hempstead, Long Island, New York
}

\begin{abstract}
In Experiment 1, four values of conditioned stimulus-unconditioned stimulus interval, or interstimulus interval (ISI) $(200,500,800$, and $1,100 \mathrm{msec})$ were studied in one trial/day acquisition of the conditioned nictitating membrane response of the rabbit. The 1,100-msec ISI group was superior to the other groups, contrary to the usual findings of ISI studies in the conditioning literature. In Experiment 2, effective conditioning levels were attained with an ISI as long as $2,200 \mathrm{msec}$, when the intertrial interval was set at either 24 or $48 \mathrm{~h}$. Results are interpreted in terms of the role of orienting responses in the conditioning process.
\end{abstract}

Most explorations of the relationship of conditioned stimulus-unconditioned stimulus (CS-US) interval (interstimulus interval-ISI) to conditioned response (CR) acquisition in rabbit nictitating membrane response (NMR) conditioning have employed massed-trial training procedures in which there are a minimum of 50 trials/day (Schneiderman, 1966; Schneiderman \& Gormezano, 1964; Smith, 1968; Smith, Coleman, \& Gormezano, 1969). On the basis of these studies, the optimal ISI is commonly reported to be $200-250 \mathrm{msec}$, with ISIs of 2,000 msec providing little or no $\mathrm{CR}$ acquisition.

Conditioning studies with small numbers of trials per day, however, indicate the need for revising the general picture of the ISI function. As the number of trials per day decreases from 120 to 5 , for example, there is a marked convergence in performance by 250 - and 1,000 msec-ISI groups (Salafia \& Terry, 1971). Administering 3 trials per day, Ferrara and Guisto (1973) found no significant ISI effect with values of 200,700 , or $1,200 \mathrm{msec}$. Moreover, with 1 trial per day (intertrial interval-ITIof $24 \mathrm{~h}$ ), a 1,250-msec group shows faster CR acquisition than a $250-$ msec group (Levinthal, 1973; Levinthal \& Papsdorf, 1970), just the opposite of the traditional ISI function reported with massed-trial training. Data from control groups for pseudoconditioning or sensitization in the Levinthal (1973) study have confirmed the $1,250-\mathrm{msec}$

This study was supported in part by research funds from Hofstra University. The authors wish to thank Jeffrey Belmont and Harvey Stern for their assistance in data collection, and Beth Levinthal for the preparation of the figures. A shortened version of this report was presented at the 1980 meeting of the Eastern Psychological Association, in Hartford, Connecticut. Reprint requests should be sent to Charles F. Levinthal, Department of Psychology, Hofstra University, Hempstead, NY 11550 .
CR performance to be due to genuine conditioning processes rather than to procedural artifacts.

The following experiments explored further the question of the ISI function with rather extended ITI conditions. Experiment 1 considered the shape of the ISI function with $1 \mathrm{trial} /$ day. Experiment 2 considered ISI values up to $2,200 \mathrm{msec}$ and ITI values up to $48 \mathrm{~h}$.

\section{GENERAL METHOD}

\section{Subjects}

The subjects were male and female New Zealand albino rabbits, approximately 100-140 days old, obtained from Wittman's Rabbitry (Yaphank, New York). All subjects were maintained by adlib access to food (Purina Rabbit Chow) and water.

\section{Apparatus}

In order to prepare the subjects for experimentation, a small loop of 0 Ethicon monofilament nylon was sutured into the subject's right nictitating membrane under local anesthesia $(0.5 \%$ Ophthaine solution). To be kept relatively immobile during the experiment, each animal was placed in a Plexiglas restraining box with an adjustable back plate, head yoke, and foam-rubber ear clamps. The trials were run with the subjects in a ventilated soundproof cubicle (LVE, Model 132-06). The shock (US) was delivered across the eyelids via tailor hooks attached to Velcro loops and then hooked onto the superior and inferior eyelids.

Movements of the nictitating membrane across the eye were monitored by a minitorque potentiometer (Conrac Corp. Model 85853) mounted on the snout via a muzzle-like assembly. The transducer was mechanically coupled to the nylon loop by a small threaded hook attached to a counterweighted lever on the shaft of the transducer. The signals from the transducer were amplified $(.5 \mathrm{~V} / \mathrm{cm})$ and recorded by a Beckman Type $R$ Dynograph at a paper speed of $50 \mathrm{~mm} / \mathrm{sec}$. A conditioned response was defined as a minimal pen deflection of $1 \mathrm{~mm}$ occurring during the ISI period, no later than $30 \mathrm{msec}$ prior to US onset.

The CS was a 93-dB SPL, $1000-\mathrm{Hz}$ tone and the US was a $2.5-$ $\mathrm{mA}, 60-\mathrm{Hz}$ shock delivered across the eyelids through the tailor hooks for $100 \mathrm{msec}$. Throughout the acquisition and habituation trials, there was a 70-dB white-noise background. 


\section{EXPERIMENT 1}

The purpose of this study was to delineate the ISI function under 1 trial/day conditions, since previously published work had not dealt with intermediate ISI values between 250 and $1,250 \mathrm{msec}$.

\section{Procedure}

Twenty-four rabbits were assigned randomly to the four ISI groups. During the experiment, two rabbits (one in the 800 -msec group and one in the 1,100-msec group) died of urinary and/or gastrointestinal disorders. Therefore, the results were tabulated and the analysis of variance was computed with unequal Ns.

The animals were sutured 1 day prior to the 2-day adaptation period. During the $11-\mathrm{min} /$ day adaptation period, the animals were attached to the transducer, wore the tailor hooks, and were enclosed in the soundproof cubicle with the white-noise background present. The acquisition period consisted of 1 trial/day for 13 days. Following each trial, the animals remained in the cubicle for a 10-min "rest" period,

ITI was approximately $24 \mathrm{~h}$. The CS duration was the specific ISI value (i.e., $200,500,800$, or $1,100 \mathrm{msec}$ ) plus the $100 \mathrm{msec}$ of the US.

\section{Results}

Analysis of variance showed a significant ISI effect in terms of the mean number of trials to the first $\operatorname{CR}[F(3,18)$ $=3.18, \mathrm{MSe}=5.87, \mathrm{p}=.049]$, to the second $\mathrm{CR}$ $[\mathrm{F}(3,18)=3.62, \mathrm{MSe}=3.85, \mathrm{p}=.033]$, and to the third $C R[F(3,18)=3.60, \mathrm{MSe}=2.31, \mathrm{p}=.034]$. Scheffé comparison tests for the group means (Table 1) showed no stepwise comparisons to be significant, but did show a significant difference between the 1,100 group and the average of the 200,500 , and 800 groups with regard to the trials to the second CR measure, $95 \%$ confidence interval limits $(-.02,-6.18)$, and the trials to the third CR measure, $95 \%$ confidence interval limits $(-.14$, -4.91). An orthogonal trend analysis was also performed on the mean performance across ISI conditions. There was a significant linear trend $[F(1,18)=5.92, \mathrm{MSe}=5.87$, $\mathrm{p}=.026]$ when considering trials to the first $\mathrm{CR}$, a significant linear trend $[F(1,18)=6.60$, MSe $=3.85, p=$ $.019]$ when considering trials to the second $C R$, and a significant linear trend $[\mathrm{F}(1,18)=4.70, \mathrm{MSe}=2.31, \mathrm{p}=$ $.044]$ and quadratic trend $[F(1,18)=4.81$, MSe $=2.31$, $\mathrm{p}=.042]$ when considering trials to the third CR.

In a combined analysis, successive CR criteria were considered as a repeated measures variable (Kehoe \& Gormezano, 1974). The split-plot analysis of variance revealed a significant ISI effect $[F(3,18)=3.71$, MSe $=$ $37.18, p=.031]$ and a significant criteria effect $[F(2,36)$

Table 1

Mean Number of Trials to Criterion in Experiment 1

\begin{tabular}{lcccc}
\hline \multirow{2}{*}{$\begin{array}{l}\text { Mean Number } \\
\text { of Trials to: }\end{array}$} & \multicolumn{4}{c}{ ISI Groups (in Milliseconds) } \\
\cline { 2 - 5 } & 200 & $\mathbf{5 0 0}$ & 800 & 1,100 \\
\hline First CR & 8.7 & 10.0 & 7.6 & 5.6 \\
Second CR & 10.3 & 11.2 & 10.0 & 7.4 \\
Third CR & 11.5 & 11.7 & 12.0 & 9.2 \\
\hline
\end{tabular}

Note-Maximum score per subject was 13 .

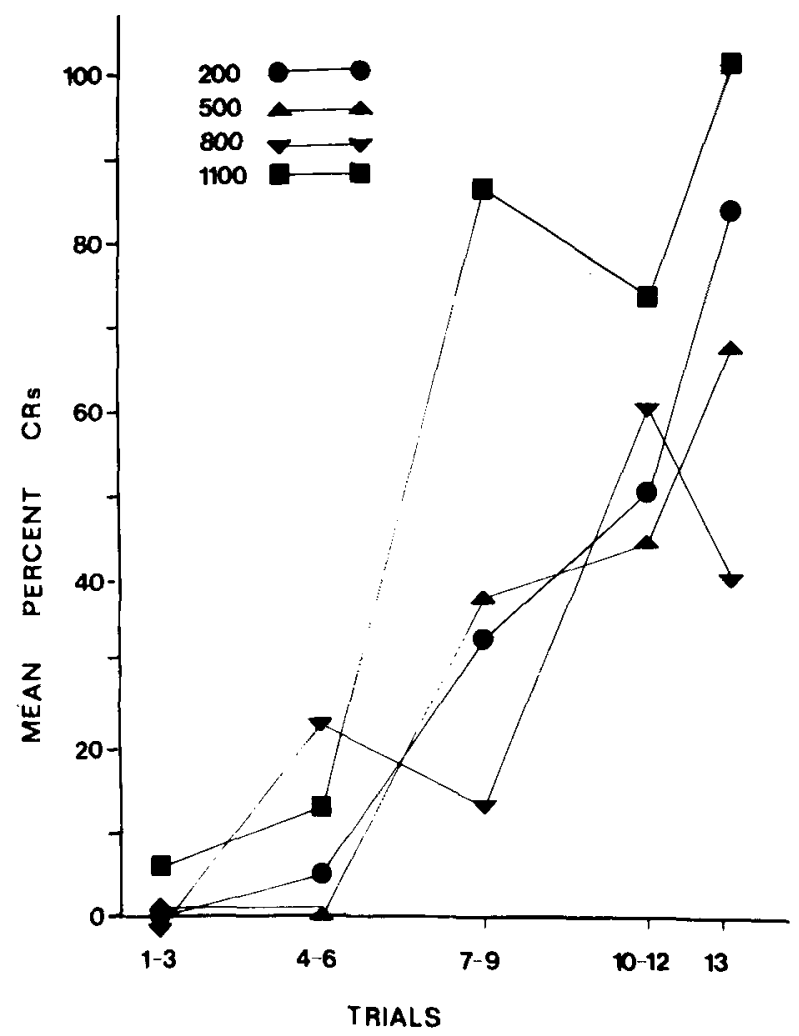

Figure 1. Mean percentage of conditioned responses (CRs) over 13 trials in groups trained with an ISI of $200,500,800$, or $1,100 \mathrm{msec}$.

$=50.44, \mathrm{MSe}=1.02, \mathrm{p}=.001]$. The interaction was nonsignificant.

It should be noted that three subjects failed to emit a CR in 13 trials, one in the 200-msec-ISI group and two in the 500-msec group.

Mean percentage of CRs for four blocks of three trials plus Trial 13 is shown in Figure 1. Analysis of variance for the first 12 trials (in four blocks of 3 trials) showed, for this dependent measure, only marginally significant effects for ISI $[F(3,18)=3.08, \mathrm{MSe}=915, \mathrm{p}=.053]$ and ISI $\times$ trial block $[\mathrm{F}(9,54)=2.05, \mathrm{MSe}=648$, $\mathrm{p}=.051]$, although there was a significant trial block effect $[F(3,54)=23.22, \mathrm{MSe}=648, \mathrm{p}<.001]$.

\section{EXPERIMENT 2}

Experiment 2 focused on the upper limits in the ISI function with widely spaced CS-US trials. The question was how far beyond $1,100 \mathrm{msec}$ the ISI could be extended and still show effective conditioning acquisition. It was expected, on the basis of the ISI literature, that the ISI function would show a decline past $1,100-1,200 \mathrm{msec}$. Specifically, it was expected in this study that a 2,200msec ISI would be associated with poorer CR acquisition than would a 1,200 -msec ISI. Control groups were included to determine how much of the conditioning potential at these extended ISIs was attributable to pseudoconditioning effects. 


\section{Procedure}

Six rabbits were assigned randomly to each of eight groups. All animals were sutured 1 day prior to the adaptation period. During this period, the animals were attached to the transducer, wore the tailor hooks, and were enclosed in the cubicle for two 10-min intervals over 2 days.

Day 1 of acquisition occurred 1 day following the adaptation. Four groups of rabbits ( $\mathrm{E}$ groups) received a single paired toneshock (CS-US) trial either once per day (24-h ITI) or once every other day (48-h ITI), with an ISI of either 1,200 or $2,200 \mathrm{msec}$. In all E-group trials, the US overlapped the last $100 \mathrm{msec}$ of CS presentation. Four other groups ( $\mathrm{C}$ groups), in a pseudoconditioning control procedure, received a single US followed $60 \mathrm{sec}$ later by a single CS that lasted either 1,300 or $2,300 \mathrm{msec}$. As with the E groups, two $C$ groups received trials with a $24-h$ ITI and two received trials with a 48-h ITI.

To be acceptable, responses had to be observed after CS onset but no later than the termination of the CS (for C groups) or $30 \mathrm{msec}$ prior to the onset of the US (for E groups). All animals remained in the experimental enclosure for $10 \mathrm{~min}$ at the end of each trial. Training consisted of 16 trials over either a 16-day or a 32-day period, depending upon the designated ITI.

\section{Results}

The effects of ISI, ITI, and conditioning procedure were assessed in a $2 \times 2 \times 2$ factorial analysis of variance.

Combined together, the four $\mathrm{E}$ groups emitted their first, second, and third $C R$ in an average of $6.0,8.5$, and 10.7 CS-US trials, respectively. The four C groups, on the average, made their respective first, second, and third responses in 11.6, 14.8, and 15.6 unpaired CS and US trials, with the 16th and last trial setting necessarily an upper limit. Analysis of variance showed $\mathrm{E}$ group versus $C$ group differences in all three criterion measures to be statistically significant, F-ratio probabilities less than $10^{-6}$. All other main effects and interactions were not significant $(\mathrm{p}>.05)$.

Comparisons of the rate of acquisition with 1 trial every day or every other day, as employed here, with rates in studies using multiple trials per day can be made by considering the mean percentage of CRs over trials. Figure 2 shows that $\mathrm{E}$ groups attained approximately $80 \%$ CRs by Trials $13-16$. In contrast, when 20 trials per day are employed (Levinthal, 1973), an $80 \%$ performance level for a 1,250-msec ISI group is not exceeded until Trials 101-120. Although they used an airpuff instead of a shock US, Schneiderman and Gormezano's (1964) data may also be illuminating. They presented 70 trials per day and included 1,000- and 2,000-msec ISI groups, roughly comparable to the ones in Experiment 2. The 1,000-msec ISI group in their study reached the $80 \%$ CR level in 351-420 trials, and their 2,000-msec ISI group failed to exceed $40 \%$ in 560 trials. It is possible that the acquisition rate with the weaker (airpuff) US may have been underestimated as compared with the present data. Nonetheless, it is fair to say that presentation of trials once per day or every other day greatly accelerates the CR acquisition rate with ISIs in the extended $1,000-2,000$-msec range. Contrary to expectation, there was no difference between the acquisition rates of the 1,100 - and $2,200-\mathrm{msec}$ groups. The equivalence of the two ISI E groups prevents, at this time, the determination of an optimal ISI value for

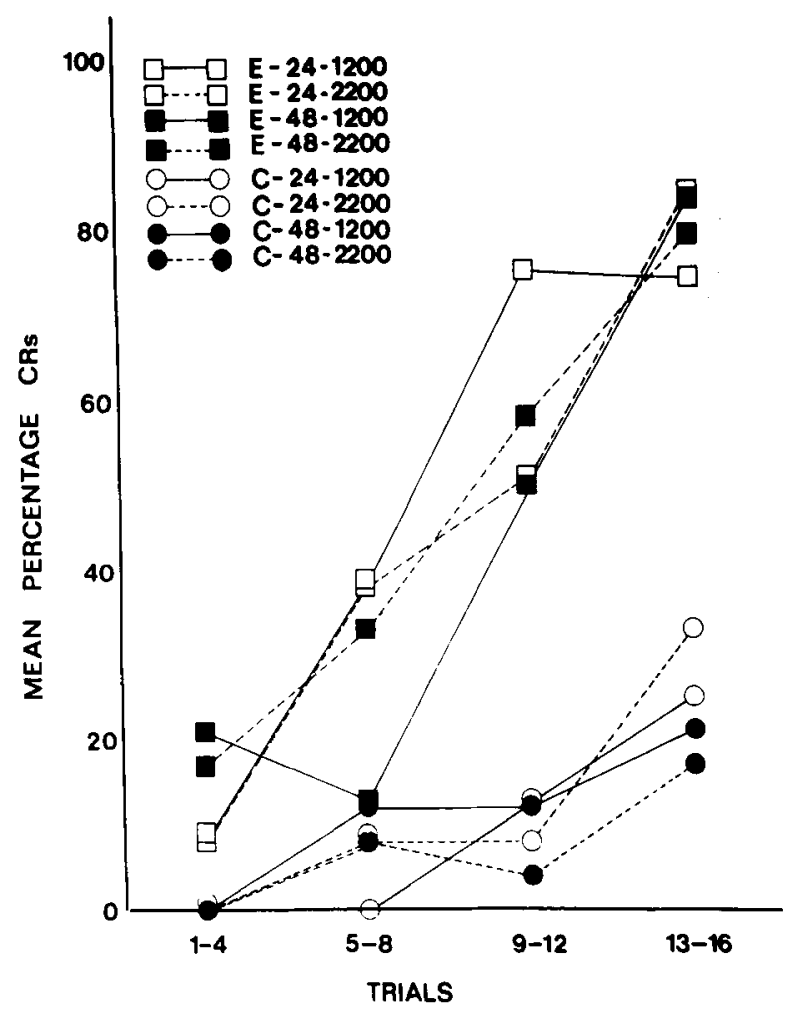

Figure 2. Mean percentage of responses over 16 paired CS-US trials (squares) or 16 unpaired CS and US trials (circles), with an intertrial interval of $24 \mathrm{~h}$ (open symbol) or $48 \mathrm{~h}$ (closed symbol) and an observation interval of $1,200 \mathrm{msec}$ (solid line) or $2,200 \mathrm{msec}$ (dashed line).

a 24-48-h ITI, although the superiority of all E groups to $\mathrm{C}$ groups confirms the earlier conclusion (Levinthal, 1973) that the results could not be attributed to pseudoconditioning.

\section{GENERAL DISCUSSION}

The results confirm earlier findings (Levinthal, 1973; Levinthal \& Papsdorf, 1970) that show an optimal ISI considerably longer than the $200-250-\mathrm{msec}$ value commonly found for this response system in the classical conditioning literature. In addition, it has been shown that, with an ISI of 1,100-2,200 msec, an extended ITI of up to $48 \mathrm{~h}$ in length can support conditioning. Taken as a whole, the results help to reaffirm the proposition expressed both in the rabbit eyelid or nictitating membrane response conditioning literature (Frey, 1970; Levinthal, 1973; Levinthal \& Papsdorf, 1970; Mis, Andrews, \& Salafia, 1970) and in the newer autoshaping literature (Jenkins, Barnes, \& Barrera, 1981; Kaplan, 1984; Lucas, Deich, \& Wasserman, 1981), that the role of the ISI parameter cannot be considered in absolute terms, that is, without consideration of other temporal parameters in the experiment. Any account of the role of ISI in classical conditioning (e.g., Gormezano, 1972; Gormezano \& Kehoe, 1981) must include an explanation for its dependency on the distribution of trials. . 
One theoretical account of the above phenomenon can be made by drawing upon a concept that was originally proposed by Frey $(1969,1970)$ to explain a shift in the optimal ISI in rabbit eyelid response conditioning to longer values as task difficulty or experimental demand increased. Frey defined a "response inhibition accompanying information processing" (RIAIP) as an inhibitory process for a response system during the early portion of a CS presentation in situations in which an animal has to respond in a limited amount of time while concurrently evaluating incoming sensory information. "Unlike more conventional notions of inhibition, RIAIP is independent of non-reinforcement operations since it depends only upon the organism's difficulty in determining which stimulus events reliably predict the US events" (Frey, 1970, p. 344).

The RIAIP can be regarded as a consequence of a CSelicited orienting response (OR), in that a situation of uncertainty can serve to provide both the impetus for an increased processing of information and a species-specific pattern of response inhibition (Lynn, 1966). Therefore, a postulated CS-elicited OR would facilitate the perceptual coding of CS-US contingencies, particularly those with a long CS-US interval. At the same time, the OR would involve a response inhibition (similar to the RIAIP) for early portions of that CS-US interval.

If response inhibition accompanies the $O R$, then there would be an inverse relationship between RIAIP habituation and trial separation, as there is between OR habituation and trial separation (Askew, 1970; Geer, 1966; Schaub, 1965). Thus, trials separated by 24 or $48 \mathrm{~h}$ would foster slow OR habituation and maintain response inhibition as compared with shorter ITIs (e.g., $60 \mathrm{sec}$ ) in massed training. The result would be a response inhibition imposed upon the early portion of the CS-US interval, perhaps lasting up to $800 \mathrm{msec}$, but a facilitation for processing CS-US contingencies up to $2,200 \mathrm{msec}$ in length. The combination of effects would be observed as a lengthening of the optimal ISI.

The mechanism behind an OR/RIAIP process remains to be determined. Levinthal (1973) proposed that, for the eyelid response and the nictitating membrane response, an eye-widening OR might act antagonistically to the respective $C R$, during the portion of the CS-US interval in which an OR would occur. Recent studies (Cegavske, Thompson, Patterson, \& Gormezano, 1976; Marek, McMaster, Gormezano, \& Harvey, 1984), however, have reevaluated what was thought to be a close interconnection between the nictitating membrane and eyelid (Deaux \& Gormezano, 1963; Last, 1961). The recent studies have concluded, on the basis of musculature and neural innervation, that the nictitating membrane response is uniphasic and separate from that of the outer eyelids. While a RIAIP cannot be posited on an output level, it is possible that there is competition on an information encoding and retrieval basis, as the onset of the $\mathrm{CS}$ presents the animal with extra demands upon a limited information-processing system.

More traditional studies in which short ITIs and/or multiple trials per day are employed would involve rapid habituation of the OR. Consequently, in the nictitating membrane response system, the well-known nonmonotonic CS-US interval function (Smith et al., 1969) would be explained by noting that habituation of the OR would cause response inhibition to recede to the first 100-200 msec of the CS-US interval. This interval of RIAIP could be considered as the "hardcore," or minimal, interval necessary for information processing with a simple, single-CS, delayed-conditioning task.

Great interest has recently been expressed in the interaction of interstimulus and intertrial intervals in the context of autoshaped keypecking in pigeons (Brown \& Jenkins, 1968). Lucas et al. (1981) have shown that, where extended ITI (e.g., up to $480 \mathrm{sec}$ ) conditions are observed, $75 \%$ of subjects trained at a 36 -sec trace ISI and $25 \%$ of subjects trained at a $120-\mathrm{sec}$ ISI acquired autoshaped keypecking, well beyond the 4-sec duration previously considered to be effective. Kaplan (1984) has explored a range of CS-US and ITI values and demonstrated a shift from conditioned excitation to conditioned inhibition with a constant unfilled CS-US gap of $12 \mathrm{sec}$ as the ITI is decreased. He has concluded that the effect of a particular CS-US contiguity depends critically on the temporal (e.g., ITI) context in which the contingency is embedded. Kaplan has drawn upon informationprocessing models of Gibbon (1981) and Wagner (1981) in stressing the importance of a ratio of ITI to CS-US gap in predicting autoshaping behavior. However, according to Kaplan, the ratios in the Lucas et al. study (10:1 or 20:1) exceed the boundaries of the Wagner model. There is no question, then, that this model would be unable to account for ratios in the present experiments, which ranged from 36,000:1 to 144,000:1. On the other hand, it is conceivable that a RIAIP notion could be useful in explaining the ISI-ITI interactions in autoshaping in the pigeon as it has been applied here for Pavlovian conditioning in the rabbit.

The findings in this study also offer a parallel in the laboratory to animal conditioning in the wild, where associations of an auditory CS and a peripheral noxious US are presumably made, even though the ISIs are quite long and any repetitions of the CS-US event are widely separated in time. In this way, the extensions of the ISI function reported here complement the literature of "bait-shy" associations (conditioned aversions) obtained in the rat (Barnett, 1963) being observed in the laboratory with pairings of a gustatory CS and a toxin US, despite ISIs of up to $75 \mathrm{~min}$ (Garcia, Ervin, \& Koelling, 1966). We suggest that ecologically relevant CS and US combinations would elicit strong and persistent orienting, leading to maximal information-processing during $C R$ acquisition. Moreover, widely spaced CS-US experiences would as- 
sist in maintaining an effective OR. Data indicating that a conditioned aversion is formed more quickly to a novel CS than to a familiar one (Revusky \& Bedarf, 1967) suggest the influence of ORs in this phenomenon, in that a novel CS would provide the greater elicitation of an OR. However, in order to provide stronger support for this speculation, it would be necessary to obtain direct records of an OR during the course of "bait-shy" learning.

The identification of ITI conditions in which CR acquisition can be obtained with very long ISIs can be useful in light of the recent increase in the number of studies exploring single-unit recording at brain sites during rabbit eyelid conditioning (Thompson, 1983; Thompson et al., 1976). Up to now, recording during CS-US intervals of up to $500 \mathrm{msec}$ may have been less than adequate for the observation of subtle neuronal patterns underlying the conditioning process. The use of longer effective ISIs obtained under extended ITIs would allow for the fourfold extension of the length of the "observation window." Furthermore, the identification of ISI conditions in which $C R$ acquisition can be obtained with very long ITIs can be useful in those studies in which there is an interest in the role of circadian thythms in conditioning. Varying the time during which, in a 24-h period, the single CS-US trial occurs would be a sensitive way of determining cyclical influences in learning for this species.

\section{REFERENCES}

AsKew, H. R. (1970). Effects of stimulus intensity and intertrial interval on habituation of the headshake response in the rat. Journal of Comparative \& Physiological Psychology, 72, 492-497.

BaRnetT, S. A. (1963). The rat: A study in behavior. Chicago: Aldine Press.

Brown, P. L., \& JenKins, H. M. (1968). Auto-shaping of the pigeon's keypeck. Journal of the Experimental Analysis of Behavior, 11, 1-8.

Cegavske, C. F., Thompson, R. F., Patterson, M. M., \& GorMEZANO, I. (1976). Mechanisms of efferent neuronal control of the reflex nictitating membrane response in rabbit (Oryctolagus cuniculus). Journal of Comparative \& Physiological Psychology, 90, 411-423.

Deaux, E., \& Gormezano, I. (1963). Eyeball retraction: Acquisition and extinction in albino rabbit. Science, 141, 630-631.

FERraRA, P., \& Guisto, T. (1973). The effect of CS habituation as a function of the CS-US interval on the classical conditioning of the nictitating membrane response in the albino rabbit. Unpublished manuscript, Hofstra University.

FreY, P. W. (1969). Differential rabbit eyelid conditioning as a function of age, ISI, and cue similarity. Joumal of Experimental Psychology, 81, 326-333.

FrEY, P. W. (1970). Within-subject analysis of the CS-US interval in rabbit eyelid conditioning. Learning \& Motivation, 1, 337-345.

Garcia, J., Ervin, F. R., \& Koelling, R. A. (1966). Learning with prolonged delay of reinforcement. Psychonomic Science, 5, 121-122.

GEER, J. H. (1966). Effects of interstimulus interval and rest-period length upon habituation of the orienting response. Journal of Experimental Psychology, 72, 617-619.

GibBon, J. (1981). The contingency problem in autoshaping. In C. M. Locurto, H. S. Terrace, \& J. Gibbon (Eds.), Autoshaping and conditioning theory (pp. 285-308). New York: Academic Press.

Gormezano, I. (1972). The stimulus trace hypothesis and investigations of defense and reward conditioning in the rabbit. In A. Black \& W. F. Prokasy (Eds.), Classical conditioning II (pp. 151-181). New York: Appleton-Century-Crofts.
Gormezano, I, KeHoe, E. J. (1981). Classical conditioning and the law of contiguity. In P. Harzem \& M. D. Zeiler (Eds.), Predictability, correlation, and contiguity (pp. 1-45). New York: Wiley.

Jenkins, H. M., BARnes, R. A., \& Barrera, F. J. (1981). Why autoshaping depends on trial spacing. In C. M. Locurto, H. S. Terrace, \& J. Gibbon (Eds.), Autoshaping and conditioning theory (pp. 255284). New York: Academic Press.

KAPLAN, P. S. (1984). Importance of relative temporal parameters in trace autoshaping: From excitation to inhibition. Journal of Experimental Psychology: Animal Behavior Processes, 10, 113-126.

KeHOE, E. J., \& Gormezano, I. (1974). Effects of trials per session on conditioning of the rabbit's nictitating membrane resporise. Bulletin of the Psychonomic Society, 2, 434-436.

LAST, R. J. (1961). Wolf's anatomy of the eye and orbit. Philadelphia: Saunders.

Levinthal, C. F. (1973). The CS-US interval function in rabbit nictitating membrane response conditioning: Single vs. multiple trials per conditioning session. Learning \& Motivation, 4, 259-267.

LEVINTHAL, C. F., \& PAPDORF, J. D. (1970). The classically conditioned nictitating membrane response: The ISI function with one trial per day. Psychonomic Science, 21, 296-297.

Lucas, G. A., Deich, J. D., \& Wasserman, E. A. (1981). Trace autoshaping: Acquisition, maintenance, and path dependence at long trace intervals. Joumal of the Experimental Analysis of Behavior, 36, 61-74.

LYNN, R. (1966). Attention, arousal and the orientation reaction. Oxford: Pergamon Press.

MareK, G. J., McMaster, S. E., Gormezano, I., \& Harvey, J. A. (1984). The role of accessory abducens nucleus in the rabbit nictitating membrane response. Brain Research, 299, 215-229.

Mis, F. W. , Andrews, J. G., \& Salafia, W. R. (1970). Conditioning of the rabbit nictitating membrane response: ISI $\times$ ITI interaction. Psychonomic Science, 20, 57-58.

Revusky, S. H., \& BEDARF, E. W. (1967). Association of illness with prior ingestion of novel foods. Science, 155, 219-220.

SALAFIA, W. R., TERrY, W. S. (1971, April). Conditioning of the rabbit nictitating membrane response as a function of number of trials per day. Paper presented at the meeting of the Eastern Psychological Association, New York.

Schaub, R. E. (1965). The effect of interstimulus interval on GSR adaptation. Psychonomic Science, 2, 361-362.

SCHNEIDERMAN, N. (1966). Interstimulus interval function of the nictitating membrane response of the rabbit under delay vs. trace conditioning. Journal of Comparative \& Physiological Psychology, 62, 397-402.

SChNEIDERMAN, N., \& Gormezano, I. (1964). Conditioning of the nictitating membrane of the rabbit as a function of CS-US interval. Journal of Comparative \& Physiological Psychology, 57, 188-195.

SMith, M. C. (1968). CS-US interval and US intensity in classical conditioning of the rabbit's nictitating membrane response. Journal of Comparative \& Physiological Psychology, 66, 679-687.

Smith, M. C., Coleman, S. R., \& Gormezano, I. (1969). Classical conditioning of the rabbit's nictitating membrane response at backward, simultaneous and forward CS-US intervals. Journal of Comparative \& Physiological Psychology, 69, 226-231.

Thompson, R. F. (1983, November). The memory trace found? Neural substrates of basic associative learning in the mammalian brain. Address given at the meeting of the Society for Neuroscience, Boston.

Thompson, R. F., Berger, T. W., Cegavske, C. F., Patterson, M. M., Roemer, R. A., Teyler, T. J., \& Young, R. A. (1976). The search for the engram. American Psychologist, 31, 209-227.

WAGNER, A. R. (1981). SOP: A model of automatic memory processing in animal behvior. In N. E. Spear \& R. R. Miller (Eds.), Information-processing in animals: Memory mechanisms (pp. 5-47). Hillsdale, NJ: Erlbaum.

(Manuscript received February 22, 1985; revision accepted for publication July 22, 1985.) 